\title{
Effects of Electron Beam Irradiation on Charpy Impact Value of Short Glass Fiber (GFRP) Samples with Random Distribution of Solidification Texture Angles from Zero to 90 Degrees
}

\author{
Michael C. Faudree ${ }^{1}$, Yoshitake Nishi ${ }^{2}$ and Michael Gruskiewicz ${ }^{3}$ \\ ${ }^{1}$ Center of Foreign Language, Tokai University, Hiratsuka 259-1292, Japan \\ ${ }^{2}$ Doctoral Graduate School of Science and Technology, Tokai University, Hiratsuka 259-1292, Japan \\ ${ }^{3}$ Premix, Inc., North Kingsville, Ohio, 44068 USA
}

\begin{abstract}
Compression-molded short-fiber GFRP-BMC panels have random distribution of solidification texture angles from zero to 90 degrees in the center of the mother panels. Hence, there is significantly lower impact strength in the panel center than in the outside. However, experimental results showed homogeneous low voltage electron beam irradiation (HLEBI) applied to the center region apparently enhances the Charpy impact values $\left(a_{\mathrm{uc}}\right) 5$ to $25 \%$. Fracture mechanism was observed to convert at $a_{\mathrm{uc}}>\sim 5.4-6.7 \mathrm{~kJ} \cdot \mathrm{m}^{-2}$ from clean to secondary microcrack proliferation and/or bends near the main crack, with increasing fracture surface area as $a_{\text {uc }}$ increased. SEM observation revealed 0.86 MGy HLEBI treated GFRP had much more polymer adhering to fibers than the untreated. This increased matrix adhesion can be explained by electron spin resonance (ESR) peaks indicating dangling bonds are generated creating repulsive forces between outer shell electrons in the polymer matrix, apparently exhibiting increased compressive stress on the fibers increasing adhesion force. Moreover, the lone pair electrons generated in the matrix may have bonded with the fibers more efficiently. For these reasons, increased fiber-matrix adhesion seen in the $0.86 \mathrm{MGy}$ samples appears to assist for more internal cracking, increasing resilience to impact of the GFRP-BMC, raising the $a_{\mathrm{uc}}$. [doi:10.2320/matertrans.M2012145]
\end{abstract}

(Received April 16, 2012; Accepted May 28, 2012; Published July 25, 2012)

Keywords: glass fiber reinforced polymer (GFRP), bulk molded compound (BMC), impact, texture, electron beam irradiation, electron spin resonance

\section{Introduction}

Glass fiber reinforced polymer (GFRP) bulk molded compounds (BMCs) are used for aerospace, automotive parts, housing for electrical wiring, and corrosion-resistant needs, hence mechanical property improvement is essential for durability and use life. BMC is composed of a thermoset plastic resin with various inert fillers, fiber reinforcement, catalysts, stabilizers, and pigments that form a viscous paste for molding. ${ }^{1)}$ Glass fiber reinforcement usually ranges from 5 to 30 mass \% while glass fiber length ranges from about 3.2 to $12.7 \mathrm{~mm}\left(1 / 8\right.$ to $1 / 2$ in). Fillers such as $\mathrm{CaCO}_{3}$ can range from $\sim 35$ to over 50 mass $\%$.

Formulations are optimized for precise dimensional control, flame resistance, high dielectric strength, corrosion and stain resistance, and color stability. BMCs have excellent flow characteristics that make them well suited for parts requiring precise dimensions and detail. Compression molding is commonly used for BMC as it can be easily produced with high productivity for mass production with a smooth and attractive surface finish. Large presses can accommodate large platen sizes making it ideal for large components. Further strengthening has always been expected to develop these lighter materials for higher durability and more efficient transports with small energy consumption for the environment.

Homogeneous low voltage electron beam irradiation (HLEBI) has been found to enhance long-fiber GFRPs, glasses such as silica glass, glass fibers, and a wide range of polymers. $^{1-7)}$ For GFRP with long fibers used for nextgeneration aircraft, HLEBI has been used to improve Charpy impact value at all fracture probabilities. ${ }^{3)}$ HLEBI often enhances the deformation resistivity (elasticity) of polymer. ${ }^{2)}$ Moreover, HLEBI often induces not only hardening, high wear resistance and sterilization for practical use of polymer, (a)<smiles>O=C(O)CCC(=O)O[Ga](O)C(CO)CO</smiles>

(b)<smiles>CC=CCC(C)c1ccccc1</smiles>

Fig. 1 Rational formulae of thermoset polyester (a) and styrene-butadiene co-polymer (b).

but also mist resistance of transparent ceramics. ${ }^{8-10)}$ Furthermore, it is also possible to enhance the interfacial strength induced by surface activation, which is generated by charging and dangling bond formation.

Figure 1 shows the rational formulae of thermoset polyester (a) and styrene-butadiene co-polymer (b). HLEBI generally cuts the atomic bonding at weak chemical bonding sites as shown in Fig. 2 and dangling bonds are formed at the terminated atoms with low dissociation energy:-6) at methylene groups $\left(\mathrm{CH}_{2}-\mathrm{CH}_{2}: 369 \mathrm{~kJ} \cdot \mathrm{mol}^{-1}\right)$, hydroxyl groups $\left(\mathrm{CH}_{3}-\mathrm{OH}\right.$ : $\left.377 \mathrm{~kJ} \cdot \mathrm{mol}^{-1}\right)$, phenyl groups $\left(\mathrm{C}_{6} \mathrm{H}_{5}-\mathrm{R}\right.$ : $<377-389 \mathrm{~kJ} \cdot \mathrm{mol}^{-1}$ where $\mathrm{R}-$ is $\mathrm{CH}_{3}-$ or $\left.\mathrm{C}_{2} \mathrm{H}_{5}-\right)$, and free-radical hydrogens $\left(\mathrm{H}-\mathrm{CH}: 427 \mathrm{~kJ} \cdot \mathrm{mol}^{-1}, \mathrm{H}-\mathrm{OC}_{2} \mathrm{H}_{5}\right.$ : $435 \mathrm{~kJ} \cdot \mathrm{mol}^{-1}$, and $\mathrm{H}-\mathrm{OOCCH}_{3}: 469 \mathrm{~kJ} \cdot \mathrm{mol}^{-1}$ ), and alkene groups $\mathrm{H}_{2} \mathrm{C}=\mathrm{CH}_{2}$ with the higher dissociation energy at $720 \mathrm{~kJ} \cdot \mathrm{mol}^{-1}{ }^{11,12)}$

Based on the radial distribution function (RDF) of silica glass, it has been found HLEBI reduces the normalized 
(a)

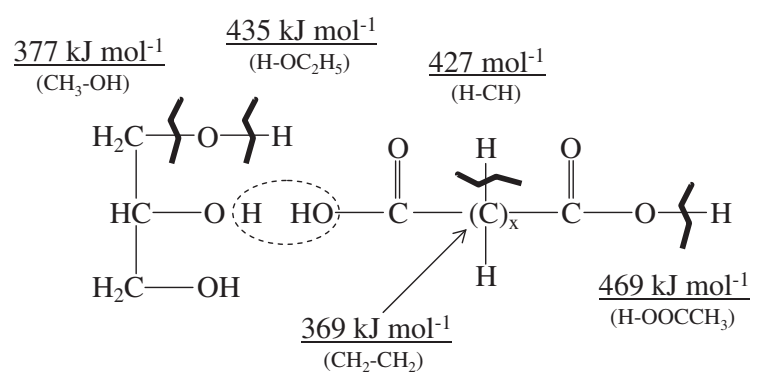

(b) $\frac{720 \mathrm{~kJ} \mathrm{~mol}^{-1}}{\left(\mathrm{H}_{2} \mathrm{C}=\mathrm{CH}_{2}\right)} \quad \frac{369 \mathrm{~kJ} \mathrm{~mol}^{-1}}{\left(\mathrm{CH}_{2}-\mathrm{CH}_{2}\right)}$

Fig. 2 Schematic illustration of thermoset polyester (a) and styrenebutadiene co-polymer (b), respectively, after electron beam irradiation showing approximate bond dissociation energies and dangling bonds. ${ }^{11,12}$ )

coordination number $N_{\mathrm{D}} / N_{\mathrm{O}}$, and raises the normalized mean atomic distance $r_{\mathrm{D}} / \mathrm{r}_{\mathrm{O}}$ resulting in volume expansion. ${ }^{7)}$ Therefore, compressive stress has been confirmed in the silica glass. Repulsive force occurs between the outer shell electrons, probably inducing compressive stress and stress relaxation similar to the role of a cushion. Therefore the effects of HLEBI on hardening, elasticity, ductility enhancements, and strengthening of ceramics, polymers and their composites can be expected.

The previous research on HLEBI has been conducted on relatively ordered one- or two-phase systems of polymers, fibers, and long-fiber reinforced polymer GFRPs and CFRPs. $^{2-7)}$ This research investigates Charpy impact of a three-phase system of compression-molded short-fiber GFRP-BMC panels containing a high percentage (55 mass\%) of $\mathrm{CaCO}_{3}$ filler that undergoes complex flow patterns. As shown in Fig. 3, the texture angles, $\theta_{t}$ (degrees) between mold flow and longitudinal direction of testing sample are $45 \pm 45^{\circ}\left(0\right.$ to $\left.90^{\circ}\right)$ for section-a, $68 \pm 7^{\circ}$ for section-b, $45 \pm 10^{\circ}$ for section-c and $17.5 \pm 17.5^{\circ}$ for section-d, respectively. In the a-sections, the impact values are much lower (10 to $70 \%$ ) than the outer sections b, c, d due to highly turbulent flow and a slower onset of cure where chains probably have a harder time moving to different configurations. Hence, the effects of EB were investigated for samples of section-a (Fig. 3 thick lines). Investigating outer sections ' $b$ ', ' $c$ ' and ' $d$ ' was beyond the scope of this study.

Figure 4 shows the center section-a where the charge of paste is first compressed characterized by rough texture with weak resin-rich areas, anisotropy of fiber and filler density gradients that exhibit high flaw sensitivity. This anisotropy can result in higher variance in impact values of section-a from panel-to-panel and at different areas within each panel. Given these conditions, it is important to strengthen parts such as electrical housing that can be exposed to outside environments to withstand possible impacts and maintain long use life.

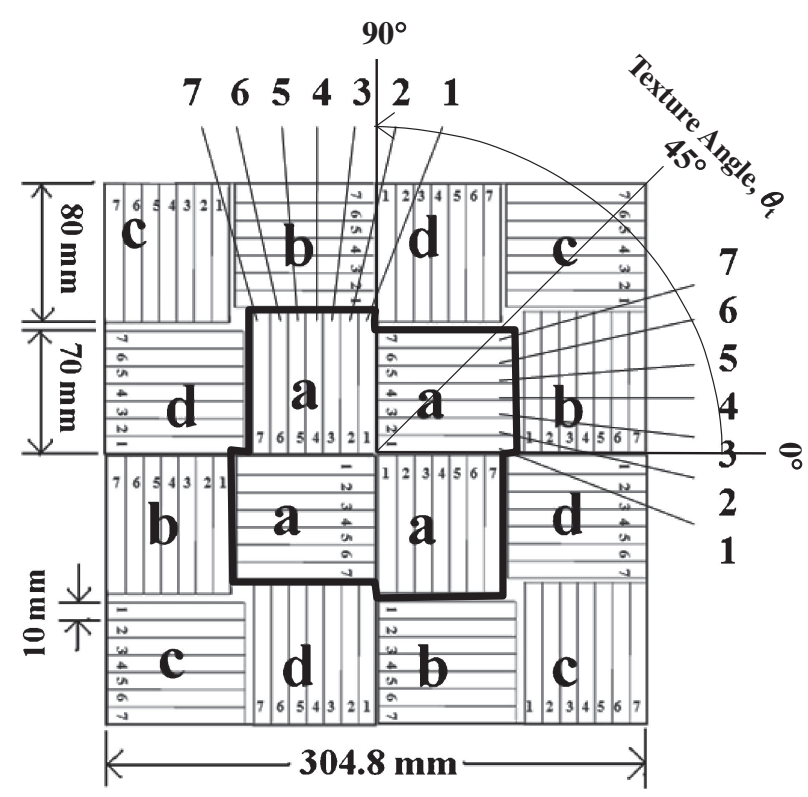

Fig. 3 Schematic of Charpy impact sample cutting from the GFRP panel. Mold flow is raidially outward from center. Samples in "a sections" in center were tested that have random distribution of solidification texture angles (from longitudinal direction of a-samples) from 0 to $90^{\circ}$.

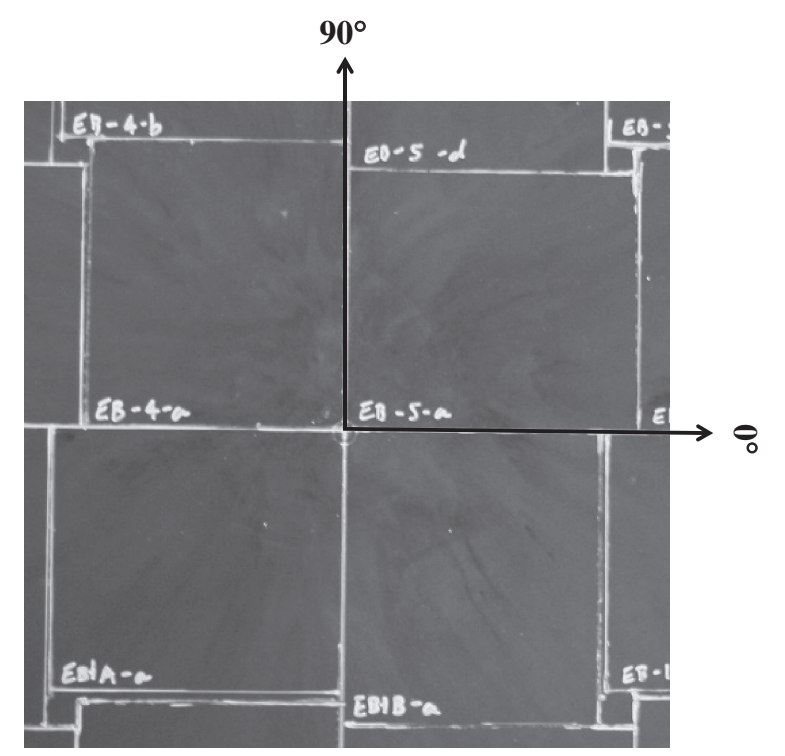

Fig. 4 Photograph of GFRP panel a-sections showing typical mold flow pattern.

Up to now, there has been no or little research on improving mechanical properties by HLEBI of short-fiber GFRP. However, since HLEBI has been found to enhance the long-fiber GFRPs, glasses such as silica glass, glass fibers, and a wide range of polymers, ${ }^{2-7)}$ it is predicted that HLEBI can enhance the Charpy impact strength 5 to $25 \%$ in the center region of the compression-molded BMC GFRP mother panels constructed with short glass fibers, $\mathrm{CaCO}_{3}$ filler and unsaturated polyester/styrene-butadiene block copolymer.

\section{Experimental}

\subsection{Preparation of GFRP}

GFRP panels $304.8 \times 304.8 \mathrm{~mm}(12 \times 12 \mathrm{in})$ and $2 \mathrm{~mm}$ thick illustrated in Fig. 3 were provided by Premix, Inc., 
North Kingsville, Ohio with components: 13.75 mass\% propylene glycol maleate polyester resin (33 mass\% styrene solution), 12.75 mass $\%$ styrene butadiene copolymer (70 mass $\%$ solution in vinyl toluene), 11 mass \% commercial Eglass fibers, 55 mass\% calcium carbonate filler $\left(\mathrm{CaCO}_{3}\right)$, 3 mass $\%$ aluminum silicate filler $(\mathrm{AlO})_{2} \mathrm{SiO}_{3}, 0.5$ mass\% magnesium hydroxide $\mathrm{Mg}(\mathrm{OH})_{2}$ and the balance proprietary. The components were mixed in a double-arm sigma blade mixer for $20 \mathrm{~min}$ at room temperature prior to molding at 5.5-6.9 MPa (800-1000 psi) in a matched metal die compression mold at $422^{\circ} \mathrm{K}\left(149^{\circ} \mathrm{C}\right)$. A single charge mass of paste was placed in the center of the mold, compressed and cure time was $2 \mathrm{~min}$. Volume fractions, $V_{\mathrm{f}}$ of glass fiber, $\mathrm{CaCO}_{3}$ filler and remaining polymer mixture were calculated to be $0.080,0.377$ and 0.543 , respectively.

Panel mold flow direction was outward from center. The material is orthotropic, where material properties in three perpendicular axes: axial, circumferential and radial are different, similar to wood. For simplicity, isotropy was assumed across the axial $2 \mathrm{~mm}$ thickness. The panel was sectioned into 4 quadrants which were further sectioned into 4 quadrants cut in spiral configuration into 'section-a', 'section-b', 'section-c' and 'section-d', respectively since flow is approximately radially outward during the compression molding process. This is in accordance with ASTM D 6110-02 (2002) which calls for specimens to be cut in both lengthwise and crosswise directions from anisotropic panels. ${ }^{13)}$

\subsection{Charpy impact tests}

Charpy impact test utilizes a drop-weight pendulum and evaluates the impact absorption characteristics and relative impact toughness of materials often used in quality control applications employed as an inexpensive and fast way to estimate reaction to impact.

To evaluate dynamic fracture toughness, Charpy impact values for GFRP samples from the center a-sections (Fig. 3) with and without HLEBI were measured. Unnotched Charpy impact samples were cut with a diamond cutter (MC-201, MARUTO) to dimensions $80 \times 10 \times 2 \mathrm{~mm}$ conforming to JIS K 7077-1991 testing standard. ${ }^{14,15)}$ Concerning variability in the a-sections, Charpy impact tests were conducted according to two data sets as shown in Table 1, where each 7letter group represents specimens 1-7 in Fig. 3 and symbols 'A', ' $\alpha$ ' and 'a' are 0.86, 0.30 EB irradiated and untreated samples, respectively. In Data Set 1 (uniform) all specimens 1-7 are given the same treatment. In Data Set 2 (alternating) specimens are given alternating treatments, for example in the first line 1, 3, 5, 7 are untreated and 2, 4, 6 are EB irradiated.

A standard impact fracture energy measurement system (Shimadzu Corp. No. 51735) was employed according to JIS K 7077-1991 ${ }^{14,15)}$ to obtain impact fracture energy, $E(\mathrm{~kJ})$ calculated in eq. (1)

$$
\begin{aligned}
E= & W R[(\cos \beta-\cos \alpha) \\
& \left.-\left(\cos \alpha^{\prime}-\cos \alpha\right)(\alpha+\beta) /\left(\alpha-\alpha^{\prime}\right)\right]
\end{aligned}
$$

where, $W, R, \beta, \alpha$ and $\alpha^{\prime}$ are: hammer mass $(W=0.86 \mathrm{~kg})$, length of hammer weight point from pivot center $(R=$ $0.21 \mathrm{~m}$ ), maximum angle after impact (Radians), start angle
Table 1 Designation of the two data sets.

\begin{tabular}{ll|ll}
\hline Data Set 1 & [uniform] & $\underline{\text { Data Set 2 }}$ & [alternating] \\
aaaaaaa & aaaaaaa & aAaAaAa & AaAaAaA \\
$\alpha \alpha \alpha \alpha \alpha \alpha \alpha$ & $\alpha \alpha \alpha \alpha \alpha \alpha \alpha$ & AaAaAaA & aAaAaAa \\
AAAAAAA & AAAAAAA & $\mathbf{a A a A a A a}$ & \\
\hline
\end{tabular}

before impact ( $\alpha=2.3$ Radians) or $132^{\circ}$, and maximum angle of a blank test, respectively. The hammer impacts the sample across its entire width with a hemispherical tip approximately $1.5 \mathrm{~mm}$ in diameter. When the Charpy impact test impact velocity, $v$ hitting the sample is calculated as: ${ }^{16)}$

$$
v=[2 g R(1-\cos \alpha)]^{0.5}
$$

where $g$ is gravitational constant $\left(9.8 \mathrm{~m} \cdot \mathrm{s}^{-2}\right)$, then $v$ of the hammer hitting the specimen is $\sim 1.74 \mathrm{~m} \cdot \mathrm{s}^{-1}$. The surface area, $A$ of the impactor hitting the sample is small so $K E / A$ is large.

Charpy impact value, $a_{\mathrm{uc}},\left(\mathrm{kJ} / \mathrm{m}^{2}\right)$ was calculated by the following equation: ${ }^{14,15)}$

$$
a_{\mathrm{uc}}=E /(b t)
$$

where $b$ and $t$ were sample width and thickness (mm), respectively. The distance between supporting points was $40 \mathrm{~mm}$. Evaluating the probability of fracture $\left(P_{\mathrm{f}}\right)$ has been a convenient method of quantitatively analyzing experimental values relating to fracture, often used in industry to determine manufacturing reliability in quality control. $P_{\mathrm{f}}$ is expressed by the following equation which is a generalized form of the median rank method: ${ }^{17)}$

$$
P_{\mathrm{f}}=(I-0.3) /\left(N_{\mathrm{s}}+0.4\right)
$$

where $N_{\mathrm{s}}$ and $I$ are total number of samples and the ascending strength order of each sample, respectively. Impact tests were carried out $30 \pm 0.5 \mathrm{~h}$ after EB irradiations.

\subsection{Homogeneous low voltage electron beam irradiation (HLEBI)}

Samples were homogeneously irradiated using an electroncurtain processor (Type LB250/15/180L), Energy Science, Inc., Woburn, MA, Iwasaki Electric Group, Ltd., Tokyo) $)^{4-6,18-20)}$ with the electron beam through a titanium thin film window attached to a vacuum chamber, $\sim 240 \mathrm{~mm}$ in diameter. A tungsten filament in the vacuum was used to generate the electron beam at an acceleration potential of $170 \mathrm{kV}$ and irradiating current of $2.68 \mathrm{~mA}$. To prevent oxidation, the samples were kept in a $1 \mathrm{~atm} \mathrm{~N}_{2}$ atmosphere with a residual $\mathrm{O}_{2}$ concentration below $300 \mathrm{ppm}$. The $\mathrm{N}_{2}$ gas molar flow rate was $89 \mathrm{~N} / \mathrm{min}$. The distance between sample and Ti window was $30 \mathrm{~mm}$. Samples were transported in a $200 \times 150 \mathrm{~mm}$ aluminum plate holder on a conveyor at a speed of $10 \mathrm{~m} / \mathrm{min}$. One sweep going one way was $0.0423 \mathrm{MGy}$ for the short time of $0.20 \mathrm{~s}$ to avoid excess heating of the sample. Repetitive applications to both side surfaces were applied to achieve the desired dose of HLEBI, with a gap interval of $20 \mathrm{~s}$ between each sweep. The resulting EB dosage was proportional to the yield value determined from the irradiation current, $I(\mathrm{~mA})$ conveyor speed, $S$ $\left(\mathrm{m} \cdot \mathrm{min}^{-1}\right)$, and number of irradiations, $N:^{21)}$ 


$$
D=0.216(I / S) N
$$

The yield value was calibrated by FWT nylon dosimeters (Far West Technology, Inc. 330-D South Goleta, CA 93117).

\subsection{Electron spin resonance (ESR) measurement}

To obtain more precise information on atomic-scale structural changes in the BMC-GFRP, the dangling bond density was obtained using an electron spin resonance spectrometer (ESR, JES-FA2000, Nippon Denshi, Ltd., Tokyo). ${ }^{2,6)}$ ESR is utilized to detect unpaired electrons by their spins $\left(m_{\mathrm{s}}= \pm 1 / 2\right)$ since electrons have a magnetic moment and spin quantum number. The unpaired electrons' magnetic moments either align themselves parallel or antiparallel to an induced magnetic field producing a peak at a particular magnetic field, $B$. ESR analysis of polymers demonstrated spectra are affected by coexistence of several kinds of radicals, effect of state of aggregation of polymer, and effect of irradiation dose and dose rate. ${ }^{22)}$ The microwave frequency range used in the ESR analysis was the X-band at $9.0374 \pm 0.0005 \mathrm{GHz}$ with a field modulation of $100 \mathrm{kHz}$. The microwave power was $1 \mathrm{~mW}$. The magnetic field was varied from 297.000 to $347.000 \mathrm{mT}$. The electron spin density was calculated using a $\mathrm{Mn}^{2+}$ standard sample. Only ESR spectra, instead of spin densities, were given.

\section{Results}

\subsection{Effect of HLEBI on impact values: Data Set 1}

Experimental results from Data Set 1 in Fig. 5(a), show applying 0.86 and 0.30 MGy HLEBI homogeneously apparently enhances the Charpy impact values $\left(a_{\mathrm{uc}}\right)$ of the GFRP near the center of the mother panel (a-sections) at all fracture probabilities $\left(P_{\mathrm{f}}\right)$ except in one sample where the high $P_{\mathrm{f}}$ of $0.94\left(9.45 \mathrm{~kJ} \cdot \mathrm{m}^{-2}\right)$ was higher than that of the $0.30 \mathrm{MGy}$. Moreover, HLEBI apparently enhanced $a_{\mathrm{uc}} 33$ and $8.7 \%$ at mid-fracture probability $\left(P_{\mathrm{f}}=0.50\right)$ at $0.86\left(8.33 \mathrm{~kJ} \cdot \mathrm{m}^{-2}\right)$ and $0.30\left(6.81 \mathrm{~kJ} \cdot \mathrm{m}^{-2}\right)$ MGy over the untreated $\left(6.26 \mathrm{~kJ} \cdot \mathrm{m}^{-2}\right)$.

Moreover, in Data Set 1 HLEBI of both 0.86 and $0.30 \mathrm{MGy}$ doses apparently raises the average $a_{\mathrm{uc}}(8.17$ and $6.88 \mathrm{~kJ} \cdot \mathrm{m}^{-2}$, respectively) of the GFRP 27.5 and $7.3 \%$, over the untreated samples $\left(6.41 \mathrm{~kJ} \cdot \mathrm{m}^{-2}\right)$. Standard deviations are $1.06(13 \%), 1.02(14.8 \%)$ and $1.24(19.3 \%) \mathrm{kJ} \cdot \mathrm{m}^{-2}$, for the $0.86,0.30$ MGy EB and untreated samples, respectively. EB at the stronger dose of $0.86 \mathrm{MGy}$ results in the lowest standard deviation of the Data Set 1.

\subsection{Effect of HLEBI on impact values: Data Set 2}

Experimental results from Data Set 2 in Fig. 5(b), show although HLEBI does not readily enhance the $a_{\mathrm{uc}}$ from $P_{\mathrm{f}}=0$ to 0.2 and 0.55 to 0.75 , the $0.86 \mathrm{MGy}$ HLEBI apparently enhances $a_{\mathrm{uc}}$ remarkably at the high values of $P_{\mathrm{f}}=0.79$ from 9.48 to $10.88 \mathrm{~kJ} \cdot \mathrm{m}^{-2}$, to $P_{\mathrm{f}}=0.96$ from 10.49 to $12.33 \mathrm{~kJ} \cdot \mathrm{m}^{-2}$, and slightly at the mid- $P_{\mathrm{f}}$ from 7.58 to $8.33 \mathrm{~kJ} \cdot \mathrm{m}^{-2}$. From the Data Set 2, $0.86 \mathrm{MGy}$ HLEBI apparently improved $a_{\mathrm{uc}} 9.9 \%$ at mid-fracture probability $\left(P_{\mathrm{f}}=0.50\right)\left(8.33 \mathrm{~kJ} \cdot \mathrm{m}^{-2}\right)$ over the untreated $\left(7.58 \mathrm{~kJ} \cdot \mathrm{m}^{-2}\right)$, although not as high as the Data Set 1 enhancement.

For Data Set 2, HLEBI of 0.86 MGy dose apparently raises the average $a_{\mathrm{uc}}\left(8.57 \mathrm{~kJ} \cdot \mathrm{m}^{-2}\right)$ of the GFRP $10.5 \%$, over the
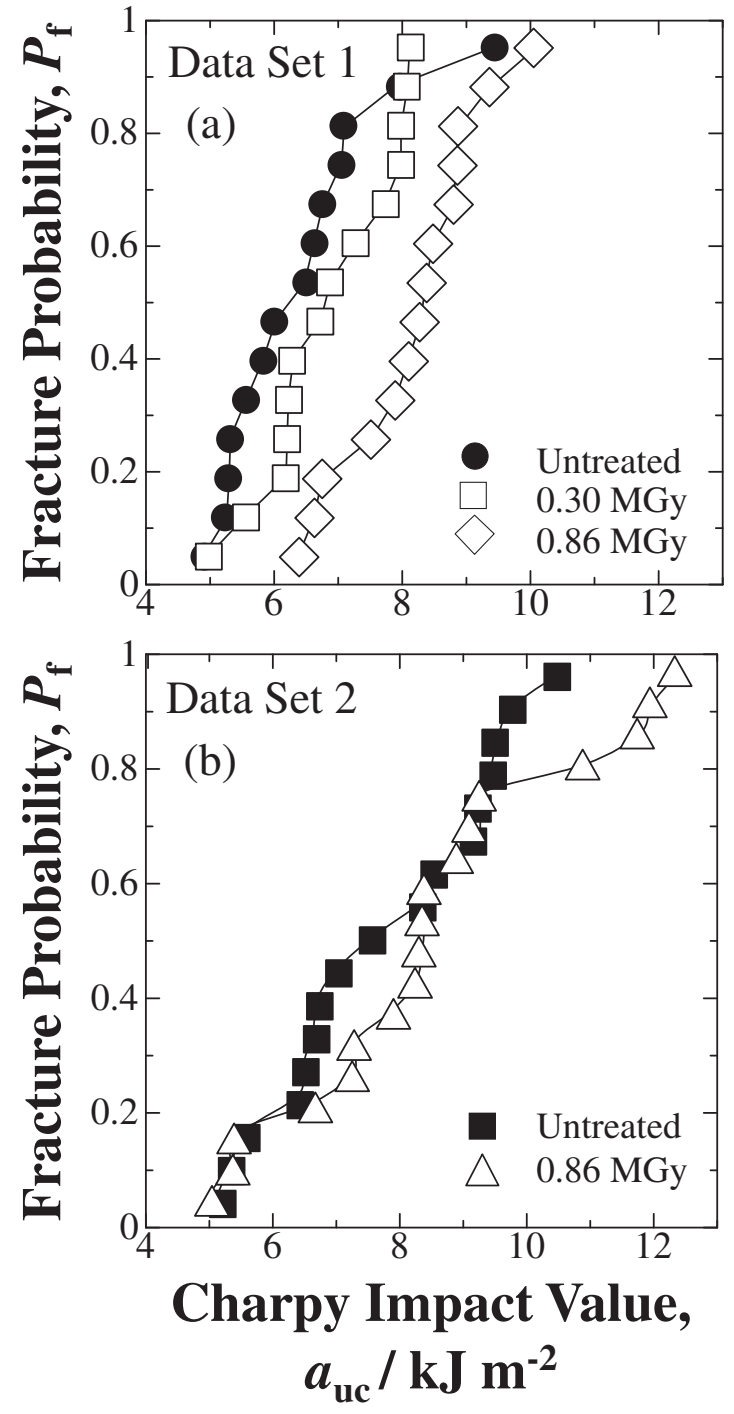

Fig. 5 Relationships between Charpy impact value and fracture probability at each EB irradiation dose for GFRP a-sections for Data Set 1 (a) and Data Set 2 (b).

untreated samples $\left(7.75 \mathrm{~kJ} \cdot \mathrm{m}^{-2}\right)$. Although standard deviations are higher for the $0.86 \mathrm{MGy}$ irradiated samples 2.22 $(25.9 \%)$, than the untreated $1.69(21.7 \%) \mathrm{kJ} \cdot \mathrm{m}^{-2}$, HLEBI raises the average $a_{\mathrm{uc}}$.

\subsection{Effect of HLEBI: Data Sets 1 and 2 combined}

For both Data Sets 1 and 2 combined average $a_{\mathrm{uc}}$ is 8.33 (1.77) and $7.15(1.63) \mathrm{kJ} \cdot \mathrm{m}^{-2}$ (standard deviations in brackets) for the $0.86 \mathrm{MGy} \mathrm{EB}$ and untreated samples, respectively with a $16.7 \%$ increase by the HLEBI.

\subsection{Effect of solidification texture angles on impact values of untreated samples}

Figures 5(a) and 5(b) show the $a_{\mathrm{uc}}$ of the untreated samples taken from the center a-sections of the two data sets, 1 and 2. The Data Set 1 had significantly lower average $a_{\mathrm{uc}}$ $\left(6.41 \mathrm{~kJ} \cdot \mathrm{m}^{-2}\right)$ than Data Set $2\left(7.75 \mathrm{~kJ} \cdot \mathrm{m}^{-2}\right)$ for untreated samples. Since there is a highly random distribution of solidification texture angles from zero to 90 degrees from panel-to-panel and at different areas within each panel, the high difference in average $a_{\mathrm{uc}}$ can be explained. The $a_{\mathrm{uc}}$ 


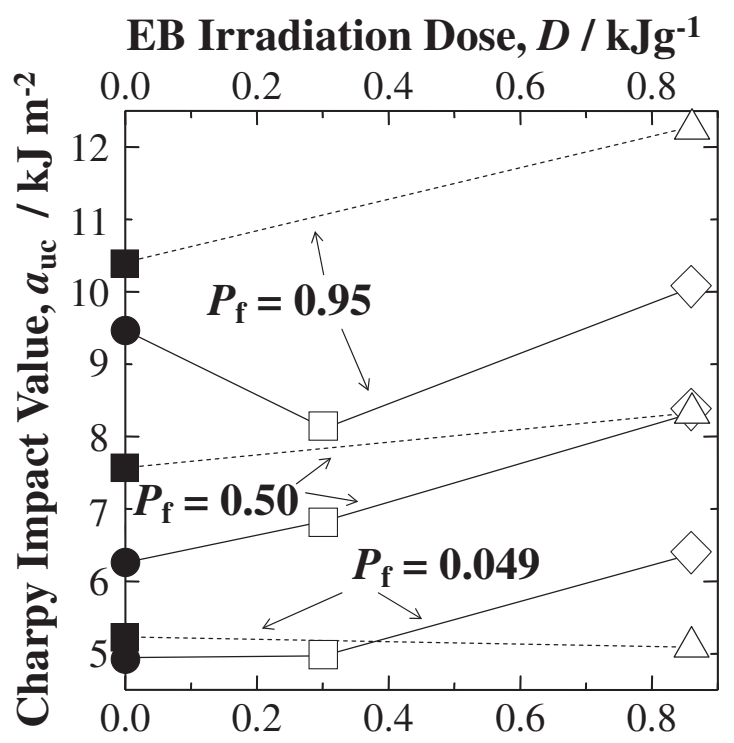

EB Irradiation Dose, $D$ / MGy

Fig. 6 Effect of EB irradiation dose on experimental impact values $\left(a_{\mathrm{uc}}\right)$ at low $\left(P_{\mathrm{f}}=0.049\right)$, mid- $(0.50)$ and high $(0.95)$ fracture probabilities of GFRP-BMC samples from Data Set 1 (solid lines) and 2 (dotted lines).

difference is an affect of the anisotropy, rather than difference between uniform and alternating samples of the two data sets.

\subsection{Effect of HLEBI at each fracture probability}

Figure 6 shows effect of EB irradiation dose on experimental impact values $\left(a_{\mathrm{uc}}\right)$ from Fig. 5 at low $\left(P_{\mathrm{f}}=0.049\right)$, mid- $(0.50)$ and high $(0.95)$ fracture probabilities of GFRPBMC samples from Data Set 1 (solid lines) and 2 (dotted lines). Overall, applying HLEBI at the higher dose of $0.86 \mathrm{MGy}$ increases the $a_{\mathrm{uc}}$ of the GFRP samples at all fracture probabilities with the exception of Data Set 2 at $P_{\mathrm{f}}=0.049$. Although $a_{\mathrm{uc}}$ at the highest experimental fracture probability of $P_{\mathrm{f}}=0.95$ is reduced from 9.45 to $8.14 \mathrm{~kJ} \cdot \mathrm{m}^{-2}$ by the 0.30 MGy EB in Data Set 1, the 0.86 MGy irradiation increases the $a_{\mathrm{uc}}$ from 9.45 to $10.05 \mathrm{~kJ} \cdot \mathrm{m}^{-2}$ in Data Set 1 and from 10.49 to 12.31 in Data Set 2 .

\section{Discussion}

\subsection{Effect of HLEBI on Weibull analysis of impact values}

The Weibull coefficient $(n)$ is one of the standard and traditional factors to compare with many other structural materials. ${ }^{23)}$ When $a_{\mathrm{uc}}$ and $a_{\mathrm{o}}$ are the measured Charpy impact value and a constant, the fracture probability $\left(P_{\mathrm{f}}\right)$ as a function of risk of rupture $\left(a_{\mathrm{uc}} / a_{\mathrm{o}}\right)$ is expressed by the following equation: ${ }^{24)}$

$$
P_{\mathrm{f}}=1-\exp \left[-\left(a_{\mathrm{uc}} / a_{\mathrm{o}}\right)^{n}\right]
$$

where $n$ is the 2-dimensional Weibull coefficient. The linear relationship is expressed as the following equation.

$$
\ln \left(-\ln \left(1-P_{\mathrm{f}}\right)\right)=n \ln a_{\mathrm{uc}}-\ln a_{\mathrm{o}}
$$

Figure 7 shows the resulting Weibull plots for each EB irradiation level and untreated for Data Sets 1 and 2. The $n$ value corresponds to the slopes of the Weibull plot relations.

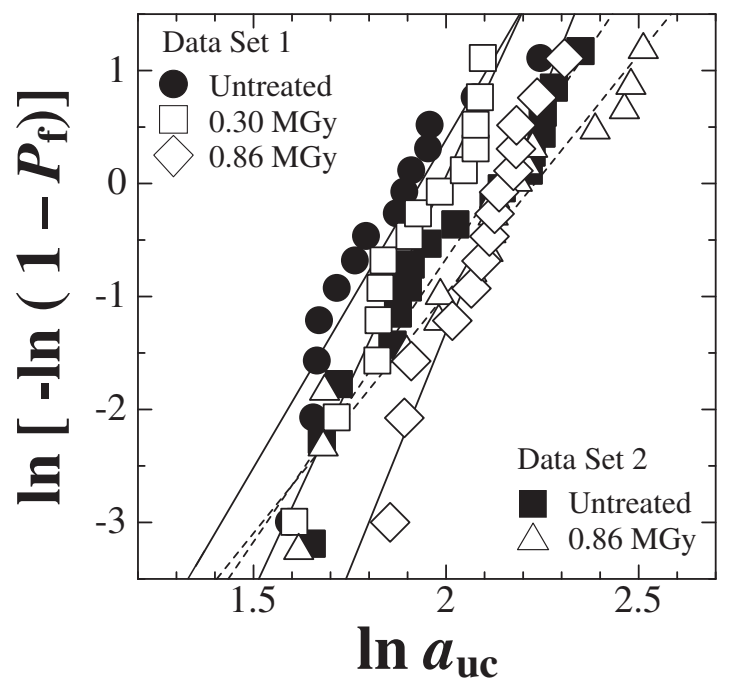

Fig. 7 Weibull plots of GFRP irradiated by electron beam at each dose for Data Set 1 (solid lines) and 2 (dotted lines).

EB Irradiation Dose, $D / \mathrm{kJ} \mathrm{g}^{-1}$

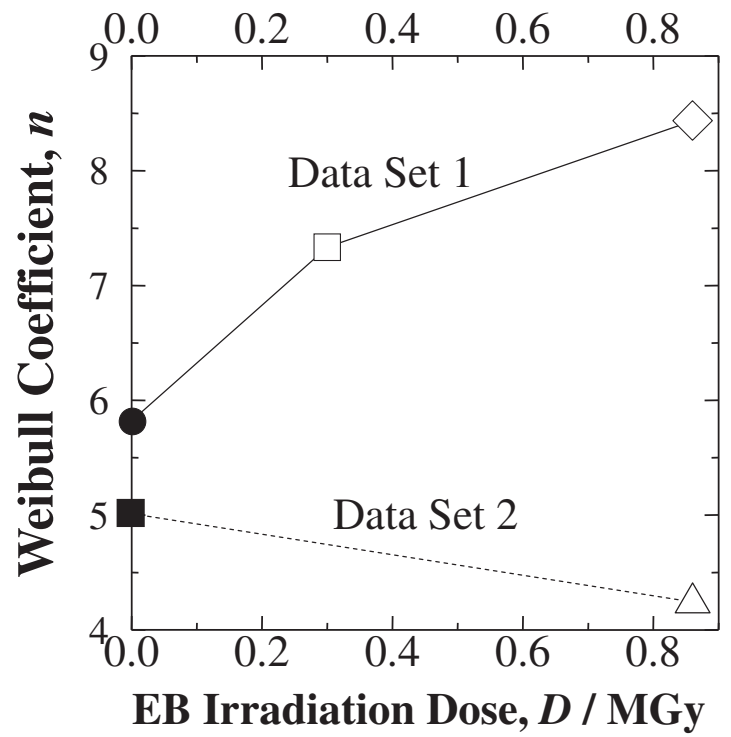

Fig. 8 Changes in Weibull coefficient $(n)$ versus EB irradiation dosages.

Figure 8 shows the $n$ obtained for each irradiation dose. In Data Set 1, the EB irradiations of 0.30 and $0.86 \mathrm{MGy}$ raised the Weibull coefficient from 5.81 (untreated) to 7.33 and 8.43, respectively. Although, in Data Set 2 the Weibull coefficient was reduced from 5.01 to 4.24 by the $0.86 \mathrm{MGy}$ $\mathrm{EB}$, the impact values were increased $9.9 \%$.

The differences in $n$ for Data Sets 1 and 2 are probably due to rough texture with weak resin-rich areas, and anisotropy of fiber and filler density gradients. Thus, the high variance in impact values of section-a from panel-to-panel and at different areas within each panel can be explained. Overcoming this, the impact values are apparently raised by applying HLEBI of $0.86 \mathrm{MGy}$.

\subsection{ESR signals}

Figure 9 shows HLEBI produces detectable ESR signals in the GFRP (a) and matrix composite without fibers (b). 


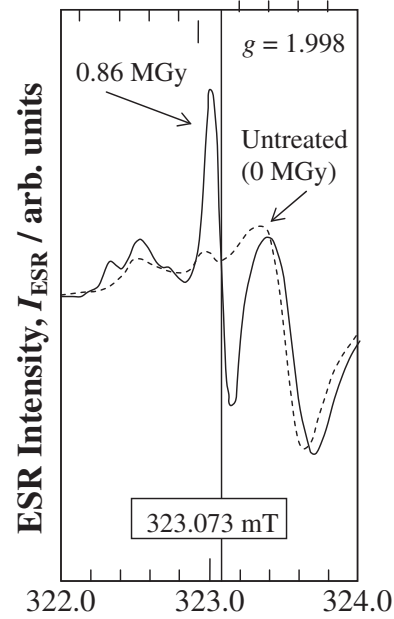

Magnetic Field, $B$ / mT

(a) GFRP

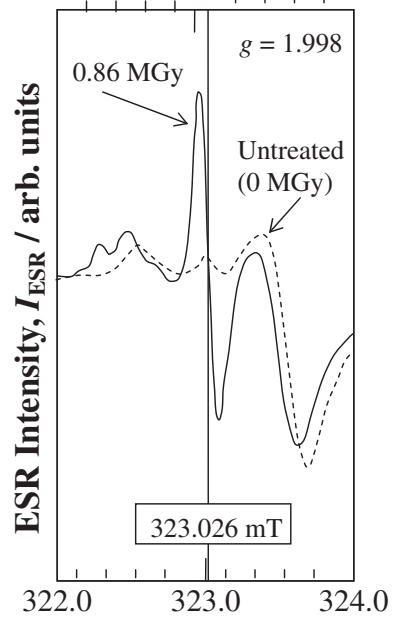

Magnetic Field, $B$ / mT

(b) Matrix composite (no glass fibers)
Fig. 9 ESR signals of GFRP (a) and matrix composite (b), respectively before (dotted line) and after $0.86 \mathrm{MGy}$ (solid line) HLEBI.

In both cases, a signal peak is generated from $0.86 \mathrm{MGy}$ EB (solid line). In contrast, no sharp peak is observed in the untreated GFRP samples (dotted line). For the GFRP and matrix composite the signal peaks are generated at inflection points of 323.073 and $323.026 \mathrm{mT}$, respectively, indicating an increase in unpaired electrons in the EB irradiated GFRP-BMC, which are probably dangling bonds. ESR signals of the GFRP and matrix composite are similar in shape and magnetic field value, thus it is possible the dangling bonds observed are from the polyester styrenebutadiene polymer.

The signal magnetic fields, $B$ of 323.073 and $323.026 \mathrm{mT}$ correspond closely to that of studies of Si-glass network $\left.(323.7 \mathrm{mT}, \mathrm{g} \text {-factor }=2.001)^{25}\right)$ and close to EB-irradiated polypropylene (PP) film at 321-322 $\mathrm{mT}$, polydimethylsiloxane (PDMS) at $322.7 \mathrm{mT}^{26)}$ and novolak-type phenol resin at $322.8 \mathrm{mT}^{21)}$ Therefore, dangling bonds are detected in the polymer.

Upfield between 323.4 and $324 \mathrm{mT}$, there is a dip in the signal which is the same in both untreated and treated samples so is not considered to be dangling bonds.

\subsection{SEM and fracture mechanism to raise $\boldsymbol{a}_{\mathrm{uc}}$}

SEM observation of entire fracture surfaces seem to show 0.86 MGy HLEBI treated GFRP has much more polymer adhering to the glass fibers than the untreated although very little is observed in the untreated. Figures 10 and 11 show SEM of fracture surfaces for the untreated (a) and 0.86 MGy treated (b) samples at lower and higher magnifications, respectively, showing the 0.86 MGy HLEBI treated GFRP has more polymer adhering to fibers (arrows) than the untreated. Figures 10 and 11 show fracture surfaces of two Data Set 1 samples selected at $P_{\mathrm{f}}=0.47$, the most improvement in $a_{\mathrm{uc}}\left(a_{\mathrm{uc}}=6.01\right.$ and $8.27 \mathrm{~kJ} \cdot \mathrm{m}^{-2}$ for untreated and $0.86 \mathrm{MGy}$, respectively). SEM observations of two additional fracture surfaces of Data Set 2 selected at $P_{\mathrm{f}}=0.96$ $\left(a_{\mathrm{uc}}=10.49\right.$ and $12.33 \mathrm{~kJ} \cdot \mathrm{m}^{-2}$ for untreated and $0.86 \mathrm{MGy}$,
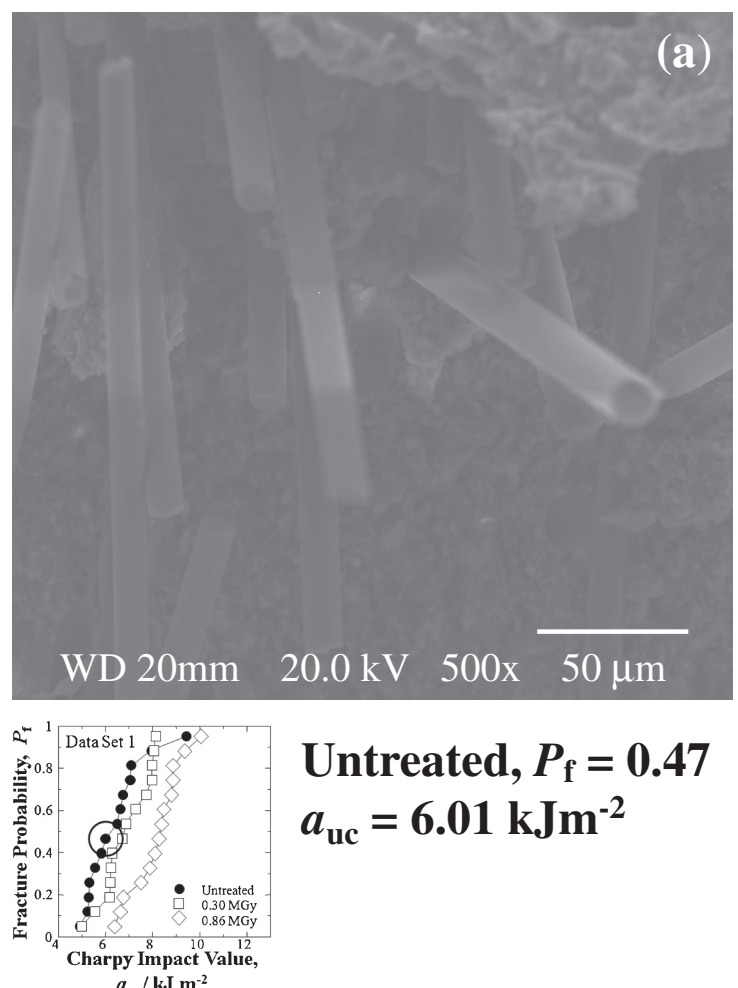

Untreated, $P_{\mathrm{f}}=0.47$ $a_{\mathrm{uc}}=6.01 \mathrm{kJm}^{-2}$ $a_{\mathrm{uc}} / \mathbf{k J ~ m}^{-2}$
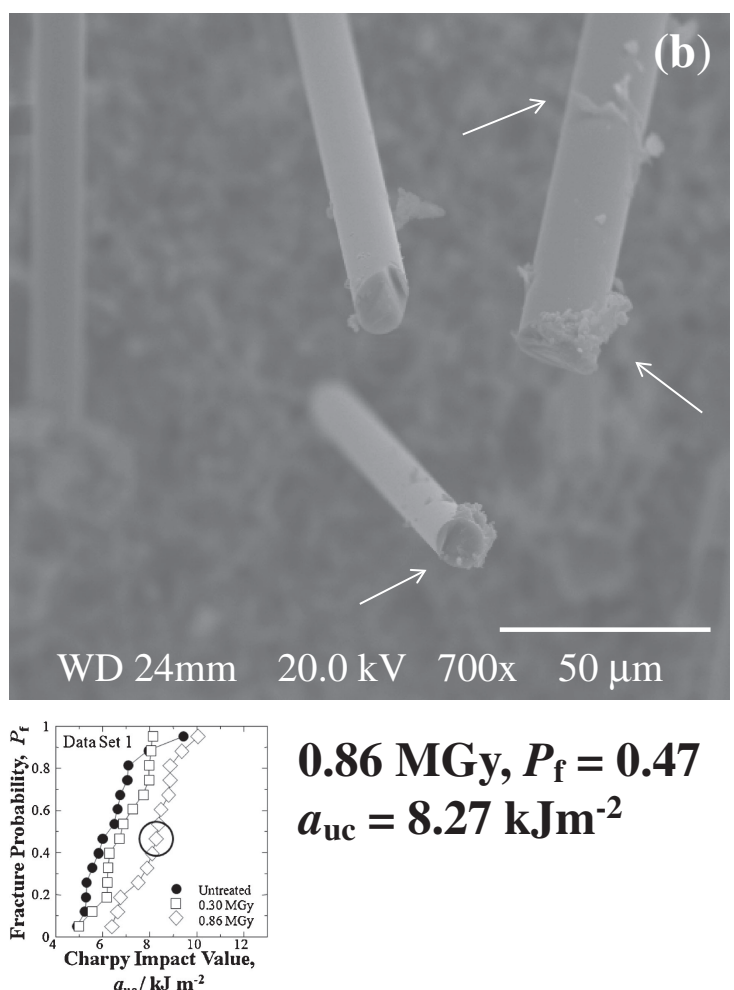

0.86 MGy, $P_{\mathrm{f}}=0.47$ $a_{\mathrm{uc}}=8.27 \mathrm{kJm}^{-2}$

Fig. 10 SEM micrograph showing untreated GFRP (a) and 0.86 MGy HLEBI treated (b) having more polymer adhering to glass fibers (arrows) than the untreated.

respectively) yield the same results. SEM observation shows the increased fiber-matrix adhesion seen in the $0.86 \mathrm{MGy}$ samples appears to assist for more internal matrix cracking, or more energy for a higher $a_{\mathrm{uc}}$. Since the fibers get stronger adhesion along the sides, the composite structure is held together more efficiently, hence cracks have to twist and 

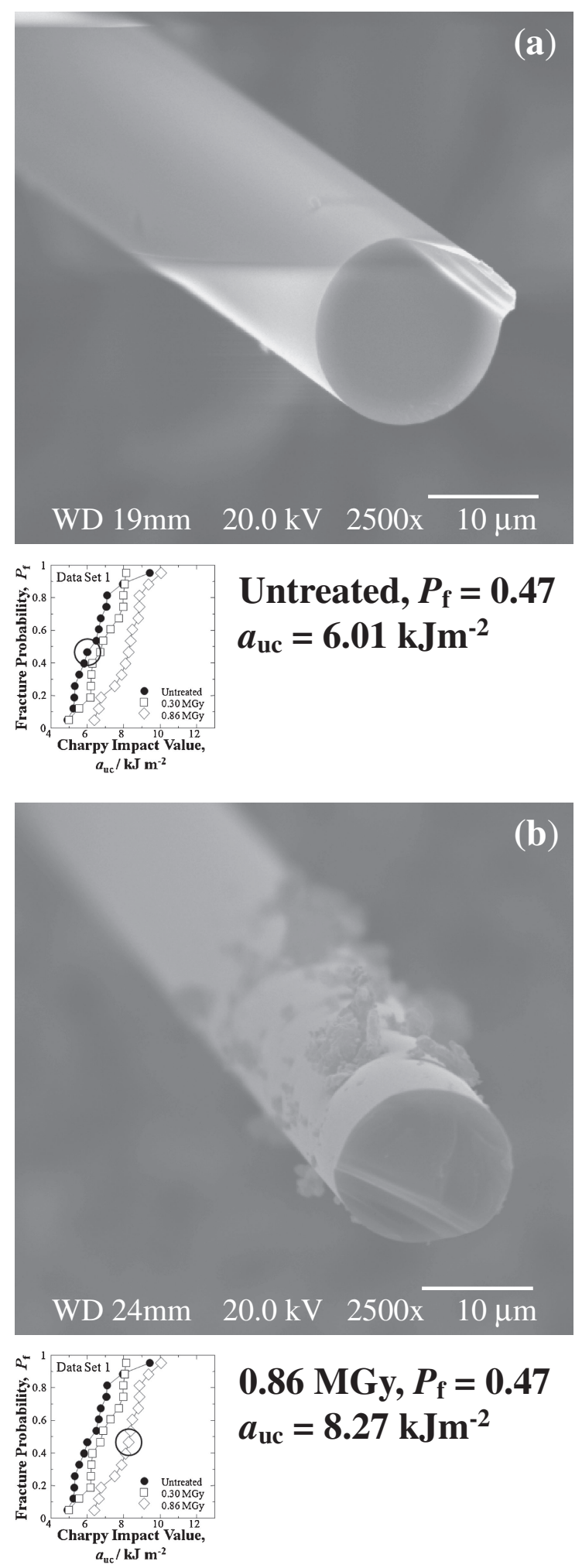

Fig. 11 SEM micrograph at high magnification of single fibers showing untreated GFRP (a) and 0.86 MGy HLEBI treated (b) having more polymer adhering to a fiber than the untreated.

branch out avoiding the compressive sites increasing impact resistance.

This increased matrix adhesion can be further explained by the ESR peaks (Fig. 9), where dangling bonds are generated creating repulsive forces between outer shell electrons in the polymer matrix. The matrix would therefore, impart increased compressive stress on the fibers increasing adhesion

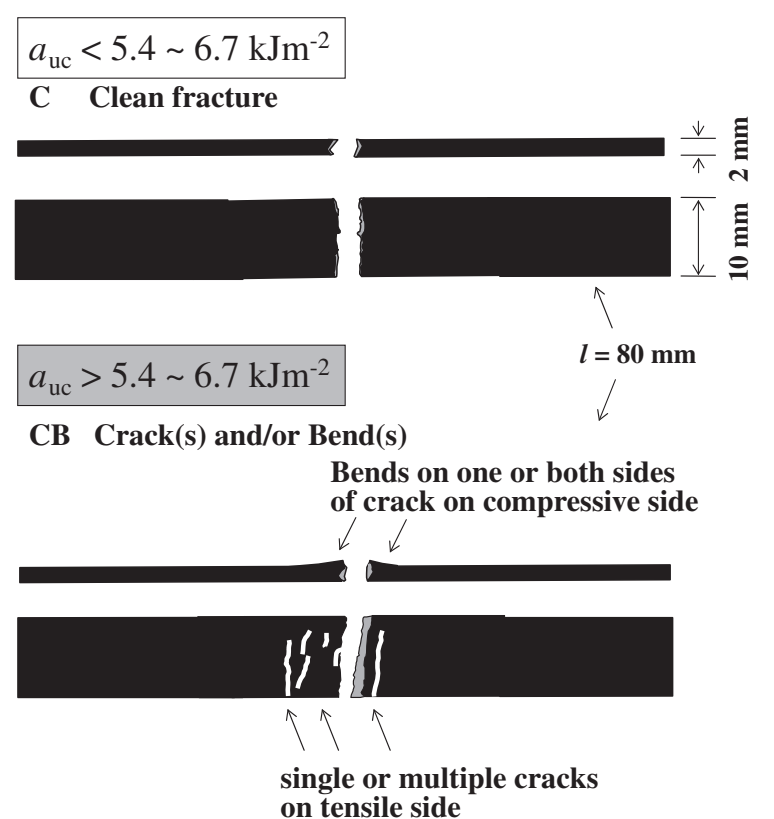

Fig. 12 Illustration showing dominant fracture mechanisms of the GFRP undergoing impact tests were a clean fracture (C) for samples with $a_{\mathrm{uc}}<5.4-6.7 \mathrm{~kJ} \cdot \mathrm{m}^{-2}$; and single or multiple bends or cracks (CB) for samples with $a_{\mathrm{uc}}>5.4-6.7 \mathrm{~kJ} \cdot \mathrm{m}^{-2}$. The trend followed independent of EB dose or untreated.

force. Moreover, the lone pair electrons in the matrix may bond with the fibers more efficiently.

Furthermore, while all Charpy impact specimens fracture completely, as $a_{\mathrm{uc}}$ increases fracture surface area is observed to increase. For example, Fig. 12 illustrates the two main fracture mechanisms for Data Sets 1 and 2 combined. At low $a_{\mathrm{uc}}$, samples exhibit a clean straight fracture perpendicular to the specimen length. At $a_{\mathrm{uc}}>\sim 5.4-6.7 \mathrm{~kJ} \cdot \mathrm{m}^{-2}$ fracture mechanism is observed to transform from the clean fracture (C), to secondary microcrack proliferation and/or bends (CB) near the main crack. The microcracks, branching from or occurring $\sim 0.5$ to $3 \mathrm{~mm}$ from the main crack, and bends are generated on the tensile and compressive sides, respectively, and are single or multiple. The trend seems to follow independent of EB dose or untreated as shown in Fig. 13 where conversions occur at $\sim 5.8,6.7$, and $\sim 5.4 \mathrm{~kJ} \cdot \mathrm{m}^{-2}$ for 0.86 and $0.30 \mathrm{MGy}$ EB irradiated, and untreated GFRP samples, respectively. Above $a_{\mathrm{uc}}>\sim 5.4-6.7 \mathrm{~kJ} \cdot \mathrm{m}^{-2}$ up to the maximum $a_{\mathrm{uc}}$ obtained at $12.33 \mathrm{~kJ} \cdot \mathrm{m}^{-2}$, fracture surface area is observed to increase in the form of more jagged shape and increasing secondary cracks visible on the tension side. For these reasons, increased fiber-matrix adhesion seen in the $0.86 \mathrm{MGy}$ samples appears to assist for more internal cracking, increasing resilience to impact of the GFRP-BMC, raising the $a_{\mathrm{uc}}$.

\section{Conclusions}

By using homogeneous EB irradiation Charpy impact strength was apparently improved 5 to $25 \%$ in the center region of compression-molded BMC GFRP panels.

(1) HLEBI of 0.86 apparently increased Charpy impact values in the GFRP at the center of the mother panel 


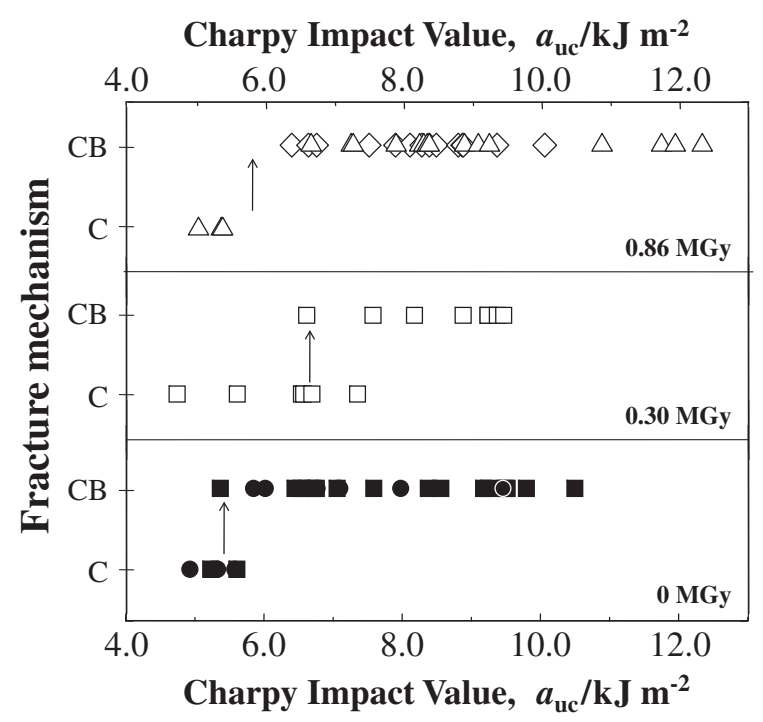

Fig. 13 Schematic diagram of main fracture mechanisms in Fig. 12 as a function of impact value for 0.86 and $0.30 \mathrm{MGy} \mathrm{EB}$ irradiated, and untreated GFRP samples for Data Sets 1 and 2 combined.

with texture angles with respect to the longitudinal direction of sample from 0 to 90 degrees.

(2) HLEBI of 0.30 MGy apparently increased Charpy impact values $\left(a_{\mathrm{uc}}\right)$ over the untreated at nearly all fracture probabilities $\left(P_{\mathrm{f}}\right)$.

(3) Impact values appeared to improve with increasing EB dose up to $0.86 \mathrm{MGy}$ in two experimental Data Sets 1 and 2.

(4) Differences in $n$ for two Data Sets 1 and 2 were probably due to high flaw sensitivity typical of GFRPBMC: rough texture with weak resin-rich areas, anisotropy of fiber and filler density gradients in the center of the mother panel. Thus, the high variance in impact values of section-a from panel-to-panel and at different areas within each panel can be explained. Overcoming this, the impact values were apparently raised $16.7 \%$ overall by HLEBI of $0.86 \mathrm{MGy}$.

(5) Fracture mechanism was observed to convert at $a_{\mathrm{uc}}>\sim 5.4-6.7 \mathrm{~kJ} \cdot \mathrm{m}^{-2}$ from clean to secondary microcrack proliferation and/or bends near the main crack, with increasing fracture surface area as $a_{\mathrm{uc}}$ increased.

(6) SEM observation revealed 0.86 MGy HLEBI treated GFRP had much more polymer adhering to fibers than the untreated. ESR peaks indicated dangling bonds are generated creating repulsive forces between outer shell electrons in the polymer matrix, apparently exhibiting increased compressive stress on the fibers increasing adhesion force. Moreover, the lone pair electrons generated in the matrix may have bonded with the fibers more efficiently. For these reasons, increased fiber-matrix adhesion seen in the $0.86 \mathrm{MGy}$ samples appears to assist for the increased internal microcompressive stress sites at the impact point, absorbing and dispersing the energy by increased internal cracking, increasing resilience to impact of the GFRP$\mathrm{BMC}$, raising the $a_{\mathrm{uc}} 5-25 \%$.

\section{Acknowledgements}

The authors extend their sincere gratitude to Mr. Shota Iizuka M.S., of Tokai University for his great assistance with the electron beam irradiation, electron spin resonance equipment and his technical knowledge. Mr. Sho Iishi is gratefully acknowledged for his great assistance with the electron microscope. Dr. Masae Kanda, Dr. Keisuke Iwata and Mr. Naoya Tsuchikura are gratefully acknowledged for their expertise and valuable input. Premix, Inc. is gratefully acknowledged for their generous support.

\section{REFERENCES}

1) M. Faudree and Y. Nishi: Mater. Trans. 51 (2010) 2304-2310.

2) H. Sato, Y. Inoue, K. Iwata, A. Tonegawa and Y. Nishi: J. Jpn. Inst. Met. 72 (2008) 520-525.

3) Y. Nishi, H. Kobayashi and M. Salvia: Mater. Trans. 48 (2007) 19241927.

4) Y. Nishi, A. Mizutani and N. Uchida: J. Thermoplastic Compos. Mater. 17 (2004) 289-302.

5) Y. Nishi, T. Toriyama, K. Oguri, A. Tonegawa and K. Takayama: J. Mater. Res. 16 (2001) 1632-1635.

6) Y. Nishi, A. Mizutani, A. Kimura, T. Toriyama, K. Oguri and A. Tonegawa: J. Mater. Sci. 38 (2003) 89-92.

7) N. Yamaguchi, K. Oguri, A. Tonegawa and Y. Nishi: J. Jpn. Inst. Met. 68 (2004) 198-201.

8) K. Oguri, N. Iwataka, A. Tonegawa, Y. Hirose, K. Takayama and Y. Nishi: J. Mater. Res. 16 (2001) 553-557.

9) K. Oguri, K. Fujita, M. Takahashi, Y. Omori, A. Tonegawa, N. Honda, M. Ochi, K. Takayama and Y. Nishi: J. Mater. Res. 13 (1998) 33683371.

10) K. Oguri, N. Iwatani, H. Izumi, A. Tonegawa, K. Takayama and Y. Nishi: Proc. 2nd Japan-France Seminar on Intelligent Materials and Structures, (University of Louis Pasteur Strasbourg, France) (1998) pp. 142-144.

11) A. James and M. Lord: Macmillan's Chemical and Physical Data, London and Basingstoke, (The Macmillan Press, Ltd., 1992) pp. 484485.

12) A. Gordon and R. Ford: The Chemist's Companion: A Handbook of Practical Data, Techniques, and References, (Wiley Interscience Publication, 1972) pp. 112-113.

13) American Society for Testing and Materials: ASTM D 6110-02 (2002).

14) Japanese Industrial Standards Committee: JIS K 7077 (1991).

15) Y. Nishi, K. Inoue and M. Salvia: Mater. Trans. 47 (2006) 2846-2851.

16) J. Splett, H. Iyer, C. Wang and C. McCowan: National Institute of Standards and Technology (NIST) Recommended Practice Guide, Computing Uncertainty for Charpy Impact Test Machine Test Results; Special publication 960-18, (US Department of Commerce: Boulder, Colorado, 2008) pp. 27-29.

17) T. Nishida and E. Yasuda: Evaluation of Dynamic Properties of Ceramics (Ceramics no rikigaku tokusei hyouka in Japanese), (Nikkan Kogaku Shimbun Sha, Tokyo, 1986) pp. 50-51.

18) D. Thomas: Plast. Rubber Int. 8 (1983) 53-57.

19) M. Dowell: Plast. Eng. 33 (1977) 31-32.

20) A. Mizutani and Y. Nishi: Mater. Trans. 44 (2003) 1857-1860.

21) H. Takei, K. Iwata, M. Salvia, A. Vautrin and Y. Nishi: Mater. Trans. 51 (2010) 2259-2265.

22) S. Ohnishi, Y. Ikeda, M. Kashiwagi and I. Nitta: Polymer 2 (1961) 119141.

23) W. Weibull: Ingeniörs vetenskaps akademien, nr. 151, (Generalstabens litografiska anstalts förlag, Stockholm, 1939) pp. 12-14.

24) W. Weibull: Ingeniörs vetenskaps akademien, nr. 153, (Generalstabens litografiska anstalts förlag, Stockholm, 1939) pp. 16-22.

25) K. Iwata, H. Kobayashi and Y. Nishi: J. Jpn. Inst. Met. 69 (2005) 10161020 .

26) Y. Nishi, H. Kawazu, H. Takei, K. Iwata, H. Kudoh and K. Mitsubayashi: Mater. Trans. 52 (2011) 1943-1948. 